\title{
Pelaksanaan pendidikan perpaduan menerusi teks KOMSAS dalam kalangan pelajar tingkatan dua
}

\author{
Implementation of unity education through KOMSAS texts \\ among the form two students \\ Chew Fong Peng \\ fpchew@um.du.my \\ Nurmaziah Majelan \\ nurmaziah.majelan65@gmail.com
}

Unversiti Malaya Kuala Lumpur, Malaysia

DOI: https://doi.org/10.37134/pendeta.vol10.6.2019

\begin{abstract}
ABSTRAK
Sentimen perpaduan di negara berbilang kaum seperti di Malaysia seringkali menjadi isu yang perlu diambil berat. Dalam konteks negara yang mempunyai masyarakat yang berbilang kaum, budaya dan agama, integrasi kaum dijadikan elemen penting dan tonggak asas dalam kestabilan negara. Kajian ini bertujuan untuk melihat bagaimana pelaksanaan pendidikan sastera menerusi teks Komsas mampu memupuk perpaduan pelajar sekolah menengah bawah di Merlimau, Melaka. Teori Weiner (1965) diaplikasikan dalam kajian ini untuk menilai pelaksanaan pendidikan teks Komsas tersebut. Soal selidik digunakan instrumen kajian untuk mengutip data daripada 103 orang pelajar Tingkatan Dua yang mempunyai latar belakang yang berbeza dari segi kaum dan pendapatan keluarga/SES. Dapatan kajian secara analisis deskriptif memperlihatkan bahawa buku teks Komsas tidak menggambarkan realiti masyarakat majmuk di Malaysia. Walaupun guru bersungguh-sungguh menarik minat pelajar, namun para pelajar masih tidak berminat dalam pembelajaran KOMSAS. Teks KOMSAS yang tinggi bahasa menyebabkan para pelajar kurang faham mengenai isi kandungannya. Dapatan analisis inferensi pula menunjukkan terdapat perbezaan yang signifikan dalam pelaksanaan pendidikan sastera perpaduan berdasarkan kaum $(F(2,100)=11.272 ; p<0.05)$. Oleh yang demikian, kajian ini mendapati kaum yang berlainan memperlihatkan perbezaan yang ketara terhadap pelaksanaan pendidikan sastera perpaduan. Justeru itu pelajar perlulah mengambil inisiatif dalam menghayati teks Komsas yang bertemakan perpaduan serta mengambil pengajaran-pengajaran dan nilai-nilai murni yang terkandung di dalamnya untuk dijadikan panduan dalam kehidupan seharian.
\end{abstract}

Kata Kunci: Sastera Perpaduan, KOMSAS, Integrasi nasional

\begin{abstract}
The sentiment of unity among multi-ethnic countries such as Malaysia, is often become the issues which need to be emphasised on. In the context of a multiracial, multicultural and multi-religion, the integration is an important element and the fundamental pillar in forming the country's stability. This study aims to evaluate how the implementation of literature education help to foster unity through KOMSAS among the lower secondary school students. Weiner's theory (1965) was applied in the study to evaluate the implementation of literature education. The questionnaire served as a research instrument to obtain the data from 103 Form Two students from different backgrounds in term of ethnic and family's monthly income/SES. The findings from descriptive analysis indicate that the KOMSAS textbook does not reflect the reality of the multiracial society in Malaysia. On the other hand, teachers are struggling to stimulate the interests among the students. However, the students are found not interested in learning the KOMSAS. The KOMSAS textbook which was written in high level of language which has caused them to hardly understand the content. On the other hand, inferential analysis findings showed that there was a significant difference in the mean score of literacy education based on ethnic $(F(2,100)=11.272$; $p<0.05)$. Thus, this study found that the different ethnic showed significant difference towards the implementation of literature education and unity. Therefore, students should take their initiative in appreciating unity-themed
\end{abstract}


literature texts as well as gaining the lessons and good values contained therein to be the guidance in their daily life.

Keywords: Unity Literature, KOMSAS, national integration

\section{PENGENALAN}

Dewasa ini, sentimen perpaduan dalam kalangan kaum yang berbilang kaum khususnya di Malaysia acapkali dibangkitkan serta dipandang berat. Dalam konteks negara yang mempunyai masyarakat yang berbilang kaum, budaya dan bangsa, perpaduan atau integrasi kaum dijadikan elemen penting dan tonggak asas dalam kestabilan negara. Negara Malaysia memiliki warganegara yang berbilang kaum termasuklah Melayu, Cina, India dan sebagainya dan menganuti agama yang berbeza seperti Islam, Buddha, Hindu, Kristian dan lain-lain. Setiap kaum masih mengamalkan adat dan budaya yang unik dan jati diri masing-masing.

Berikutan itu, sistem pendidikan dianggap sebagai medium utama dalam meningkatkan semangat perpaduan dalam generasi muda rakyat Malaysia khususnya dalam kalangan pelajar di sekolah yang seharusnya dipupuk sejak dari bangku sekolah. Sistem pendidikan bukan sahaja berperanan dalam mendidik pewaris bangsa menjadi lebih berilmu pengetahuan semata-mata, namun sistem pendidikan juga dilihat sebagai satu wadah untuk menyemaikan nilai-nilai murni dalam jiwa para pelajar untuk mengamalkan semangat integrasi nasional. Matlamat pendidikan tersebut perlu dilaksanakan mengikut keperluan dan kesesuaian masyarakat Malaysia yang berbilang kaum agar dapat berfungsi dengan baik sebagai medium yang berperanan penting dalam memupuk semangat perpaduan yang kukuh dalam diri anak bangsa.

\section{PERNYATAAN MASALAH}

Menoleh kepada pembangunan integrasi nasional dalam diri masyarakat, isu-isu perkauman sememangnya dianggap perkara sensitif yang sering dibangkitkan dengan tujuan mencetuskan provokasi dalam kalangan rakyat (Mohd Ridhuan Tee Abdullah, 2015).Bagi mengatasi isu-isu perkauman daripada terus berlarutan dan tanpa kesudahan, pihak Kementerian Pendidikan Malaysia mengambil langkah inisiatif dengan mewujudkan satu subjek baru, iaitu kesusasteraan Melayu yang dilihat penting dalam menyemai keharmonian dan kemakmuran dalam masyarakat serta negara (Ani Omar, 2015). Proses perpaduan dalam kalangan masyarakat ternyata bukan satu perkara yang dianggap mudah dan lancar seperti yang diharapkan namun ianya merupakan suatu proses yang kompleks dan berhubung kait dengan anggota masyarakat (Mohd Ridhuan Tee Abdullah, 2015).

Melalui pelaksanaan Komponen Sastera dalam Bahasa Melayu (KOMSAS) dalam Bahasa Melayu, ia dapat melahirkan bakal generasi yang berwibawa dan kukuh jati diri kerana karya sastera dilihat mencerminkan realiti hubungan fungsional dalam masyarakat yang berbilang kaum khusus di sekolah sebagaimana yang dinyatakan oleh Mahzan Arshad, Abdul Jalil Othman, Nurfatimah Awang Da (2011) bahawa kesusasteraan Melayu sememangnya memainkan peranan yang penting dalam memupuk perpaduan, keharmonian, kesefahaman dan kemakmuran kaum di Malaysia

Di sebalik pelaksanaan pendidikan KOMSAS dalam Bahasa Melayu, ia perlu dilihat dari sudut pelbagai perspektif untuk meninjau sejauh mana keberkesanan pelaksanaannya dalam mewujudkan perpaduan dalam kalangan pelajar. Keberkesanan itu dapat diukur dengan melihat sejauh mana keupayaan tenaga pengajar dan pelajar-pelajar dalam memahami, mendalami dan menghayati KOMSAS yang meliputi pelbagai elemen penting dalam kehidupan yang acapkali dibangkitkan sebagai isu utama (Mohd Mahzan Awang, Noor Azam Abdul Rahman \& Abdul Razaq Ahmad, 2015). Antara isu hangat yang menjadi perdebatan sekarang ialah isu perpaduan dan integrasi nasional.

Nurhamizah Hashim, NurYuhanis Mohd Nasir, Hashim Ismail, Eizah Mat Hussain, dan Nurul Syahidah Tahir (2018) memperlihatkan proses bagi sesebuah karya sastera dipilih berdasarkan kriteria yang memenuhi tiga dimensi utama yang diberikan penekanan dalam menentukan sesebuah teks KOMSAS. Dimensi yang dimaksudkan terdiri daripada dimensi bahan yang merujuk kepada teks yang dipilih itu hendaklah berkualiti, terbaik, sesuai dan menepati kurikulum kebangsaan. Kedua ialah 
dimensi guru. Sesebuah teks yang dipilih haruslah mampu dilaksanakan oleh guru dalam proses pengajaran dan pembelajaran. Hal ini bermakna teks tersebut hendaklah sesuai dengan kepakaran guru dalam menyampaikan pengajaran kepada pelajar. Akhir sekali merupakan dimensi pelajar yang memberi perhatian kepada teks yang mudah untuk difahami oleh pelajar, dekat dengan kehidupan pelajar, boleh menarik minat pelajar, mencetuskan kreativiti pelajar dan seterusnya teks itu boleh dihayati oleh pelajar. Dimensi pelajar merupakan aspek yang amat penting kerana hal ini merupakan hasil yang boleh dilihat sama ada sesebuah teks KOMSAS itu membawa kepada kesan positif mahupun sebaliknya.

Walau bagaimanpun, berdasarkan kajian Chew Fong Peng (2009), didapati bahawa buku teks KOMSAS tidak menggambarkan realiti masyarakat berbilang kaum khususnya di Malaysia. Seterusnya, pelajar kurang berkawan dengan pelajar yang berlain bangsa. Selain itu, para pelajar didapati kurang berminat dalam pembelajaran KOMSAS yang dilihat lebih berpusatkan orang Melayu. Manakala para pendidik yang mengajar subjek Bahasa Melayu jarang mengaitkan elemen integrasi nasional dengan pembelajaran seharian sama ada di dalam kelas mahupun di luar kelas (Chew Fong Peng, 2009; Yong Hie Hie, Ku Hasnita Ku Sams u, Zatul Himm ah Adnan, Mohd Daud Awang \& Adlina Ab Halim, 2018). Selama ini, guru-guru Bahasa Melayu lebih cenderung mengajar KOMSAS berpandukan pendekatan struktur, iaitu menganalisis aspek dalaman teks sastera dari segi tema, persoalan, watak, plot, latar dan gaya bahasa. Hal ini menyebabkan peranan pendidikan sastera sebagai dipandang remeh dalam mencorakkan integrasi nasional dalam kalangan pelajar (Chew Fong Peng, 2006).

Seterusnya, Mahzan Arshad, Abdul Jalil Othman dan Nurfatimah Awang Da (2011) bersependapat menyatakan bahawa kajian dalam bidang sastera yang bersifat perpaduan tidak begitu pesat seperti di negara barat. Justeru itu, kurangnya maklumat, perkembangan serta data terkini berkaitan perpaduan kaum yang hidup dalam kepelbagaian budaya, bangsa dan agama terutamanya di Malaysia. Rentetan itu, teks KOMSAS yang dilihat mencerminkan realiti kehidupan yang berlatar belakang kaum, budaya dan cara hidup bermasyarakat yang terdiri daripada pelbagai kaum, penambahbaikan teks KOMSAS perlu diterapkan dalam bahasa Melayu bertujuan memupuk nilai-nilai positif seperti perpaduan, hormat-menghormati dan saling membantu antara satu sama lain.

Selain itu juga, pendidikan sastera juga membantu dalam pembentukan personaliti pelajar yang baik kira mengira bangsa, budaya dan agama yang dianuti seseorang pelajar itu. Pembentukan personaliti yang menarik dapat disuburkan melalui pemikiran positif serta menghayati jalan cerita yang berunsur nilai-nilai murni yang digambarkan oleh penulis dalam sesebuah karya. Pendidikan sastera bukan sahaja membentuk perwatakan seseorang pelajar, pendidikan sastera juga dapat meningkatkan kemahiran berbahasa. Justeru itu, penyerapan elemen kepelbagaian budaya sesama secara tidak langsung dapat diteliti serta dihayati membentuk bangsa Malaysia yang peka terhadap budaya kaum lain khususnya negara yang berbilang bangsa. Oleh itu, pendidikan sastera perlu diperkukuhkan bagi menjadi teras dalam pengajaran dan pembelajaran di sekolah agar pelajar lebih pemahaman berkaitan sastera perpaduan dapat dipupuk dalam jiwa setiap pelajar. Pendidikan sastera juga dilihat mampu menyemai semangat kesatuan dalam kalangan pelajar di sekolah telah lama diterapkan dalam bidang pendidikan. Justeru kajian ini akan menumpukan fokus kepada pendidikan sastera menerusi KOMSAS dari segi teks dan pelaksanaan selain mengkaji perbezaan pelaksanaan pendidikan sastera mengikut latar belakang sosial.

\section{OBJEKTIF DAN SOALAN KAJIAN}

Objektif-objektif kajian yang ingin dikaji terdiri daripada:

1. Mengetahui kekerapan teks KOMSAS yang menerapkan elemen perpaduan.

2. Menilai pelaksanaan pendidikan sastera perpaduan menerusi teks KOMSAS.

3. Mengenal pasti perbezaan pelaksanaan pendidikan sastera perpaduan menerusi teks KOMSAS mengikut kaum dan status sosio-ekonomi (SES). 
Soalan kajian dibina berdasarkan objektif kajian seperti berikut:

1. Apakah tahap kekerapan teks KOMSAS yang menerapkan elemen perpaduan?

2. Apakah keadaan pelaksanaan pendidikan sastera perpaduan menerusi teks KOMSAS?

3. Adakah terdapat perbezaan yang signifikan antara pelaksanaan pendidikan sastera perpaduan menerusi teks KOMSAS mengikut kaum dan SES?

Daripada soalan kajian tiga, hipotesis kajian dirumuskan seperti berikut:

$\mathrm{H}_{01}$ : Tidak terdapat perbezaan yang signifikan antara pelaksanaan pendidikan sastera perpaduan menerusi teks KOMSAS mengikut kaum.

$\mathrm{H}_{\mathrm{a} 1}$ : Terdapat perbezaan yang signifikan antara pelaksanaan pendidikan sastera perpaduan menerusi teks KOMSAS mengikut kaum.

$\mathrm{H}_{02}$ : Tidak terdapat perbezaan yang signifikan antara pelaksanaan pendidikan sastera perpaduan menerusi teks KOMSAS mengikut pendapatan keluarga/SES.

$\mathrm{H}_{\mathrm{a} 2}$ : Terdapat perbezaan yang signifikan antara pelaksanaan pendidikan sastera perpaduan menerusi teks KOMSAS mengikut pendapatan keluarga/SES.

\section{TINJAUAN LITERATUR}

Kajian dilaksanakan oleh Mohd Mahzan Awang, Noor Azam Abdul Rahman, Noraziah Mohd Amin dan Abdul Razaq Ahmad (2016) untuk menjalankan analisis terhadap buku teks Bahasa Malaysia tingkatan 4 dan 5. Peribahasa Melayu yang telah dianalisis dengan menggunakan teknik tema merangkumi tiga peringkat, yakni pengkaji menyenaraikan peribahasa yang terkandung dalam keduadua buku teks, mentafsirkan makna peribahasa, dan mengekodkan tema. Dalam konteks ini, persetujuan bersama dicapai bersama mengenai maksud dan kesesuaian tema bagi kesemua peribahasa Melayu yang dipilih dan dianalisis. Hal ini bermakna kesemua tema yang dikemukakan dalam hasil kajian ini perlu dipersetujui secara mutlak oleh tiga orang pengekodan. Hasil kajian mempersembahkan empat tema utama yang telah dicatatkan, iaitu adaptasi sosial, muafakat, jati diri dan tanggungjawab. Setelah dianalisis, kesemua peribahasa Melayu yang dianalisis memfokuskan kepada semangat kekitaan dalam masyarakat termasuklah kepentingan keharmonian kehidupan. Dengan perkataan lain, pembelajaran peribahasa Melayu bukan hanya mendidik pelajar tentang ketinggian pemikiran tamadun Melayu, namun ia juga berperanan menjadi bahan pengajaran dan pembelajaran yang menitikberatkan perpaduan kaum dalam kalangan rakyat Malaysia. Namun begitu, hasil kajian menunjukkan hanya terdapat sedikit peribahasa berkaitan perpaduan dalam buku teks Bahasa Malaysia Tingkatan 4 dan 5 diterapkan.

Selain itu, Ibrahim Rosli (2016) menjalankan kajian untuk menganalisis konsep perpaduan kaum dalam novel terpilih Abdullah Hussain. Kajian ini menggunakan kaedah analisis teks secara kualitatif untuk menganalisis elemen integrasi kaum yang terkandung dalam teks yang dipilih. Secara keseluruhan, pengkaji menganalisis dua karya nukilan Abdullah Hussain iaitu Interlok dan Buih di Atas Air. Teori Cerminan Masyarakat Lukacs diaplikasikan dalam kajian itu sebagai garis panduan untuk meninjau hubungan antara dua novel penulisan Abdullah Hussain dengan perkaitan cara hidup masyarakat yang berlatar belakangkan kaum dan budaya yang wujud di Malaysia. Hasil analisis kajian ini mendapati bahawa pemilihan tema, plot dan juga watak yang terdapat dalam kedua-dua novel nukilan Abdullah Hussain ini menggambarkan realiti latar belakang kehidupan masyarakat yang berbilang kaum. Jelasnya, kedua-dua novel karya Abdullah Hussain jelas memaparkan elemen integrasi nasional dalam pelbagai aspek kehidupan bermasyarakat. Antaranya termasuklah suasana sosiobudaya, ekonomi dan politik masyarakat Malaysia. Selain itu, dapatan analisis kedua-dua novel ini juga menonjolkan cerminan citra budaya masyarakat majmuk di Malaysia yang secara langsung membantu 
dalam menyumbang ke arah keadaan yang lebih baik, harmoni dan bersatu padu dalam melicinkan pembangunan dalam negara ini.

Dari segi lain, sarjana lain lebih tertumpu kepada topik perpaduan dalam kehidupan sosial seharian. Kajian dijalankan oleh Suzana Sulaiman (2013) bertujuan untuk mengenal pasti tahap perpaduan etnik daripada segi kehidupan seharian yang terbina dalam kalangan pelajar Program Diploma Universiti Malaysia Perlis yang meliputi pelbagai etnik yang berbeza latar belakang. Kajian ini dijalankan dengan menemu bual 20 orang pelajar program Diploma Tahun Dua, Sesi 2012/2013 di Universiti Malaysia Perlis (UniMAP), Perlis. Dalam kajian ini, pengkaji kajian ini telah menyediakan satu set soalan temu bual yang mengandungi latar belakang responden dan soalan-soalan mengenai kehidupan seharian pelajar di kolej kediaman. Dapatan hasil kajian mendapati bahawa hubungan etnik dalam kehidupan seharian pelajar adalah bertahap sederhana dan pelajar memperlihatkan kecenderungan bagi memberikan pandangan yang lebih positif mengenai hubungan antara etnik dalam menjalani seharian di kolej kediaman yang masih belum menyesuaikan diri dalam persekitaran kolej kediamannya. Justeru itu, aktiviti-aktiviti yang boleh mengukuhkan hubungan antara pelajar perlu diperbanyakkan dengan beberapa cadangan yang disarankan dalam kajian ini.

Hussein Haji Ahmad \& Haneza Ab. Hamid (2015) menjalankan kajian terhadap semangat patriotisme dari dua dimensi, iaitu semangat patriotisme terhadap negara dan masyarakat Malaysia. Untuk mewujudkan masyarakat Malaysia yang mencintai negara dan pada masa yang sama berkongsi semangat patriotisme dalam kalangan masyarakat umum Malaysia, proses menanamkan nilai-nilai patriotisme mesti bermula pada usia muda. Kajian yang menggunakan kaedah kuantitatif berdasarkan data yang dikumpulkan melalui instrumen kajian dan dianalisis menggunakan SPSS (Statistical Package for Social Sciences) versi 21. Sebuah sekolah menengah kebangsaan di Daerah Klang, Selangor yang mempunyai pelajar pelbagai kumpulan etnik telah dipilih sebagai responden kajian. Sampel kajian terdiri daripada 169 orang pelajar tingkatan empat yang dipilih secara persampelan bertujuan daripada sekolah tersebut. Pada dasarnya, kajian ini mendapati bahawa pendidikan sekolah menengah adalah platform terbaik untuk penanaman dan pengembangan konsep perpaduan negara untuk Malaysia. Dalam konteks ini, peranan pengurusan sekolah diperiksa untuk menentukan pelaksanaan konsep perpaduan nasional di sekolah dan kesannya terutamanya pada pemanfaatan semangat patriotisme dalam kalangan pelajar sekolah menengah etnik. Hubungan antara proses pengurusan sekolah dengan perkembangan patriotisme pelajar juga diuji untuk menentukan sama ada sekolah itu dapat mempengaruhi rasa semangat patriotisme pelajar kepada negara. Keputusan menunjukkan bahawa peranan pengurusan sekolah memberi kesan terhadap perasaan patriotisme para pelajar. Walau bagaimanapun, kajian itu juga mendapati bahawa proses pelaksanaan program mengenai patriotisme yang dilakukan oleh pihak pengurusan sekolah tidak mempunyai pengaruh yang signifikan terhadap semangat patriotisme. Ini menunjukkan peranan dan inisiatif yang dimainkan oleh sekolah masih tidak mencukupi dalam membangun dan menanamkan konsep perpaduan nasional dalam kalangan pelajar sekolah menengah

Di samping itu, Yong Hie Hie, Ku Hasnita Ku Samsu, Zatul Himmah Adnan, Mohd Daud Awang dan Adlina Ab Halim (2018) menumpukan perhatian kepada peranan guru sebagai agen sosialisasi dalam membentuk perpaduan kaum di sekolah. Guru merupakan agen yang lebih berautoriti, sekali gus dapat memberi impak yang lebih positif ke arah pembentukan perpaduan kaum di sekolah. Para guru terutamanya di peringkat sekolah rendah merupakan agen sosialisasi yang penting dalam menyatupadukan murid-murid yang terdiri daripada pelbagai kaum, seterusnya membentuk kesedaran generasi muda mengenai tanggungjawab mereka sebagai seorang warganegara. Walau bagaimanapun, terdapat guru yang mewujudkan provokasi perkauman serta melakukan pengasingan murid-murid mengikut kaum, latar belakang ekonomi dan agama agar mereka dapat mencapai keputusan yang baik dalam peperiksaan, dan sebahagiannya juga mengabaikan peranan mereka sebagai agen sosialisasi dan membentuk perpaduan kaum kepada murid-murid. Oleh itu, kajian ini dijalankan untuk meneliti peranan guru sebagai agen sosialisasi dalam membentuk perpaduan kaum. Kaedah kualitatif melalui teknik perbincangan kumpulan berfokus dijalankan bagi mencapai objektif kajian, melibatkan seramai enam orang guru yang terdiri daripada guru Melayu, Cina dan India. Mereka merupakan guru yang berkhidmat di enam buah sekolah rendah daripada Sekolah Kebangsaan (SK), Sekolah Jenis Kebangsaan Cina (SJKC) dan Tamil (SJKT) di daerah Petaling. Hasil kajian menunjukkan terdapat empat peranan utama dalam memupuk dan membentuk perpaduan kaum, iaitu penyampai maklumat 
ilmu kenegaraan; ilmu perpaduan; ilmu kebudayaan kaum; dan sebagai suri teladan kepada pelajar ke arah pemupukan perpaduan kaum.

\section{KERANGKA TEORI}

Teori Myron Weiner (1965) sangat meluas digunakan dalam bidang pendidikan selain bidang politik. Menurut Teori Weiner (1965), integrasi nasional membawa maksud "a process of bringing together ......... into a single territorial unit and establisment of a national identity". Weiner (1965) turut menyatakan integrasi nasional merupakan satu langkah menyatupadukan satu kelompok yang terpisah ke dalam satu kesatuan dan merupakan satu proses yang berlanjutan sehingga dapat memupuk semangat ketaatan kepada negara.

Dalam konteks Malaysia, konsep integrasi nasional teori weiner (1965) berkait rapat dengan konsep perpaduan nasional Kementerian Pembangunan dan Perpaduan Negara (1972) yang ingin dicapai.

Satu proses pembentukan sebuah masyarakat yang mengikut kepercayaan dan prinsipprinsip Rukun negara. Dalam masyarakat ini, tiap-tiap individu bukan sahaja mempunyai identiti dan nilai-nilai yang sama sebagai rakyat Malaysia, tetapi juga memiliki impian agar gegala memecahkan perkauman dan unsur kedaerahan rakyat yang berbeza kumpulan etnik tidak lagi wujud.

Dalam kajian ini, pengkaji berpendapat bahawa dalam proses mencapai perpaduan atau kesepaduan kaum yang terdiri daripada pelbagai etnik yang berbeza bukanlah satu impian di Malaysia, tetapi boleh dicapai melalui kesefahaman dan sikap bertolak ansur antara satu sama lain. Namun bagi mewujudkan keharmonian dan integrasi nasional yang lebih erat dalam arus kemodenan, adalah mustahil dicapai tanpa semangat nasiolisme yang kuat. Tambahan pula, semangat nasiolisme setiap rakyat di negara ini adalah berpandukan kepentingan dan identiti bersama.

Di Malaysia, integrasi elit-massa dapat dilihat menerusi semangat kesepaduan dan kebersamaan kuasa melalui kuasa politik yang bergabung antara kaum. Dalam konteks ini, Malaysia mencapai integrasi budaya dan integrasi tingkah laku dengan cara yang unik dan tersendiri. Kepelbagaian aktiviti budaya yang dijalankan dalam aktiviti sosial mampu mengukuhkan ikatan perpaduan antara kaum yang berbeza latar belakang. Sebagai contoh hari kebudayaan, rumah terbuka dalam bulan perayaan dan persembahan hari kemerdekaan yang dianjurkan melibat semua kaum di Malaysia.

Dalam mencari langkah merangka pembinaan perpaduan kaum, pengkaji membina konsep kesesuaian teks KOMSAS, guru sebagai tenaga pengajar dan penerimaan pelajar dalam proses pengajaran dan pembelajaran KOMSAS menerusi teori utama, iaitu Teori Myron Weiner berdasarkan Rajah 1 yang dipaparkan berikut. 


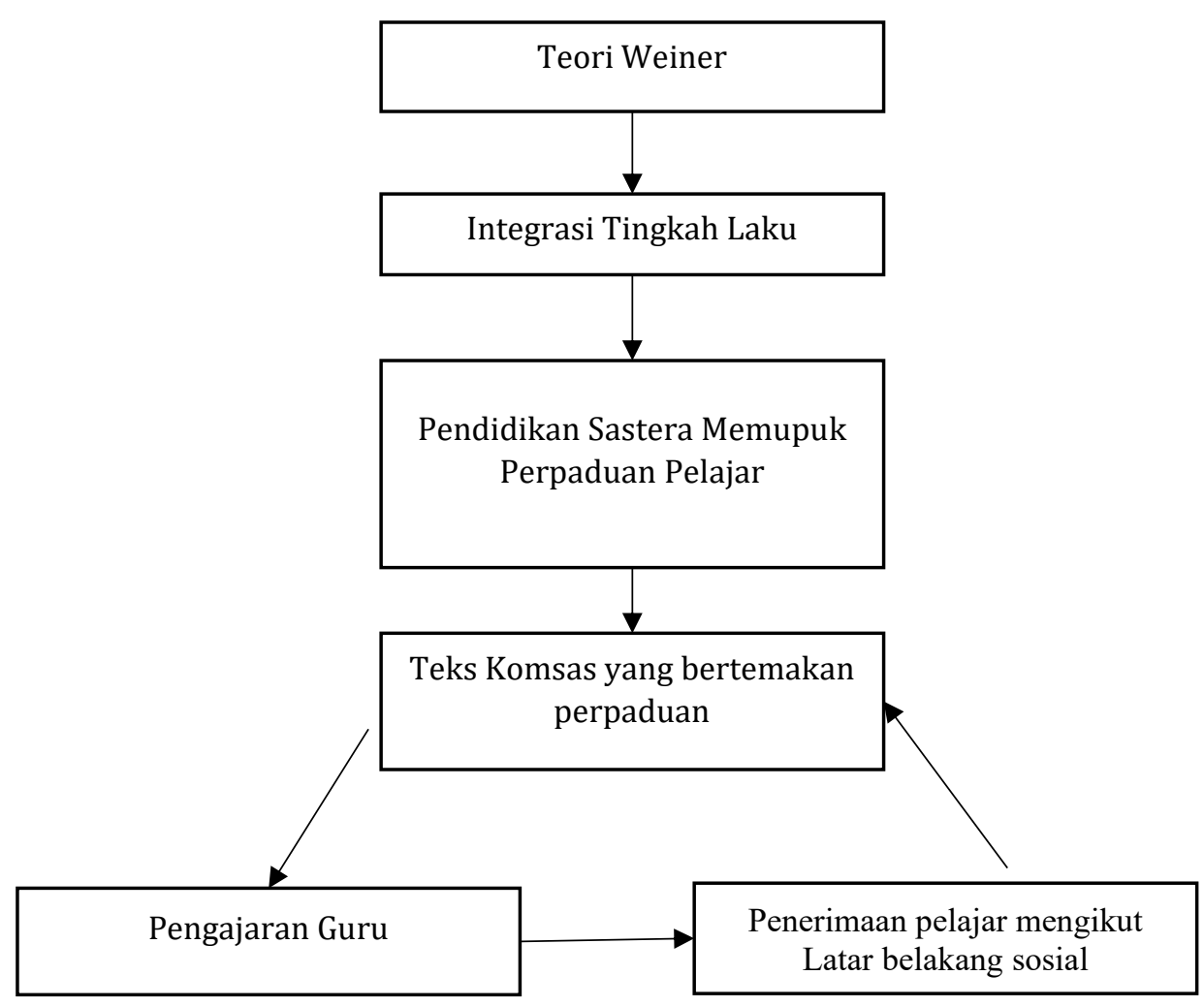

Rajah 1 : Kerangka Teori Kajian Pendidikan Sastera Memupuk Perpaduan Pelajar Tingkatan dua

Dalam skop kajian ini, pengkaji memfokuskan kepada tiga aspek, iaitu buku teks, guru dan pelajar. Kesesuaian bahan teks yang diterapkan dalam pengajaran dan pembelajaran KOMSAS perlu dititikberatkan dari segi kesesuaian peringkat umur dan sesuai untuk dijadikan bahan bacaan bagi peringkat sekolah (Nurhamizah Hashim, Nur Yuhanis Mohd Nasir, Hashim Ismail, Eizah Mat Hussain \& Nurul Syahidah Tahir, 2018). Contohnya, teks sastera dalam peperiksaan awam seperti Pentaksiran Tingkatan Tiga (PT3) atau Sijil Pelajaran Malaysia (SPM) yang dipilih hendaklah sesuai atau mewakili anak-anak muda yang mendorong mereka dalam membina sahsiah yang baik dan dapat memupuk semangat kekitaan dalam kehidupan bermasyarakat berbilang bangsa.

Daripada aspek guru dalam mengajar KOMSAS dengan baik sangat diperlukan kerana ianya akan menjadi penanda aras amalan guru yang berkesan dalam pelaksanaan pengajaran dan pembelajaran untuk menambahbaikkan tahap profesionalisme guru cemerlang (Chong Chee Keong, Muhammad Faizal A. Ghani \& Zuraidah Abdullah, 2016) termasuk guru Bahasa Melayu khususnya dalam mengajar KOMSAS. Kualiti dalam pengajaran guru dinilai daripada mutu maklumat dan kesungguhan guru dalam menyampaikan pengajaran supaya pelajar-pelajar lebih berminat belajar dan memahami pembelajaran yang dipelajari. Pengajaran yang dimaksudkan adalah kesesuaian pengajaran guru dengan aras kebolehan pelajar-pelajar serta kesediaan pelajar dalam mendalami sesuatu ilmu yang disampaikan oleh guru.

Penerimaan para pelajar sendiri adalah aspek yang penting dalam memastikan sesuatu pengajaran dan pembelajaran itu tercapai. Aspek ini memfokuskan kepada aspek latar belakang sosial pelajar mempengaruhi perbezaan penerimaan ilmu yang diajar oleh guru. Dalam kajian ini, aspek kaum dan status sosioeonomi (SES) atau pendapatan keluarga akan dijadikan fokus kajian. Rajah 1 di atas menunjukkan pengkaji menggabungjalinkan konsep-konsep yang terlibat seperti kesesuaian teks KOMSAS yang bertemakan perpaduan, peranan guru sebagai pelaksana pendidikan sastera perpaduan dan penerimaan pelajar terhadap pengajaran dan pembelajaran KOMSAS di sekolah akan dikaji. 


\section{METODOLOGI KAJIAN}

Kajian ini berbentuk tinjauan dengan menggunakan soal selidik sebagai alat kajian. Pengkaji mengadaptasikan soal selidik Chew (2009) untuk menjawab soalan-soalan kajian yang dibangunkan dalam kajian ini. Soal selidik tersebut kemudian diedarkan kepada responden kajian untuk mendapatkan data dan maklumat berkaitan pandangan pelajar terhadap pendidikan teks KOMSAS untuk memupuk perpaduan kaum. Soal selidik terbahagi kepada dua bahagian iaitu Bahagian A tentang maklumat latar belakang responden termasuk kaum, jantina dan pendapatan bulanan keluarga. Bahagian B pula terbahagi kepada dua konstruk kajian yang mengandungi 23 item soalan tertutup yang perlu dijawab oleh responden kajian, yakni teks KOMSAS yang berkaitan perpaduan (16 item) dan pelaksanaan pendidikan perpaduan (13 item).

Kajian ini dijalankan di dua buah sekolah menengah kebangsaan di daerah Merlimau, Melaka. Negeri Melaka dipilih kerana ia merupakan Bandaraya Bersejarah di Malaysia. Di sini pernah berlaku pertembungan budaya yang istemwa antara Melayu, Cina dan India sejak zaman Melayu tradisional yang ketika itu merupakan Pusat Budaya yang kukuh dan kaya dengan warisan bersejarah dan diiktiraf UNESCO. Sekolah yang dipilih dalam kajian ini sangat sesuai dijadikan lokasi kajian kerana bilangan pelajar yang ramai dan juga terdiri daripada latar belakang kaum, agama dan budaya yang pelbagai. Kaedah pensampelan bertujuan digunakan untuk memilih seramai 103 orang pelajar tingkatan dua yang terdiri daripada pelbagai latar belakang dipilih mengikut keperluan pengkaji.

Terlebih dahulu, kajian rintis dijalankan terhadap 30 orang pelajar Tingkatan 2 di salah sebuah sekolah menengah kebangsaan di Kuala Lumpur. Nilai alpha Cronbach pada aras 0.85, menunjukkan instrumen tersebut adalah tekal dan boleh dipercayai. Justeru ia diedarkan kepada responden kajian dalam kajian sebenar. Setelah itu, data yang dipungut itu dianalisis mengikut ujian statistik yang sesuai, iaitu statistik deskriptif dan statistik inferensi. Statistik deskriptif bertujuan untuk mempersembahkan data-data yang mudah dan difahami pembaca untuk menjawab soalan kajian 1 dan 2 dalam bentuk kekerapan, peratus, min dan sisihan piawai, manakala statistik inferensi pula bertujuan untuk dibuat generalisasi keputusan kajian yang telah dijalankan. Statistik inferensi dalam kajian ini melibatkan ANOVA satu hala untuk menjawab soalan kajian 3.

\section{PROFIL RESPONDEN KAJIAN}

Keseluruhan responden kajian yang terdiri daripada pelajar tingkatan dua yang berbeza latar belakang jantina, kaum, agama dan SES dari dua buah sekolah menengah kebangsaan di daerah Merlimau, Melaka. Taburan responden kajian dipaparkan dalam jadual 1.

Jadual 1. Latar Belakang Responden Kajian

\begin{tabular}{|c|c|c|c|}
\hline Bil & Kategori $(\mathrm{N}=103)$ & Kekerapan & Peratusan (\%) \\
\hline 1. & $\begin{array}{l}\text { Jantina } \\
\text { Lelaki } \\
\text { Perempuan }\end{array}$ & $\begin{array}{l}52 \\
51\end{array}$ & $\begin{array}{l}50.5 \\
49.5\end{array}$ \\
\hline 2. & $\begin{array}{l}\text { Kaum } \\
\text { Melayu } \\
\text { Cina } \\
\text { India } \\
\text { Lain-lain }\end{array}$ & $\begin{array}{l}36 \\
36 \\
31\end{array}$ & $\begin{array}{l}35.0 \\
35.0 \\
30.0\end{array}$ \\
\hline 3. & $\begin{array}{l}\text { Agama } \\
\text { Islam } \\
\text { Buddha } \\
\text { Hindu } \\
\text { Kristian } \\
\text { Lain-lain } \\
\end{array}$ & $\begin{array}{l}36 \\
34 \\
28 \\
5 \\
0 \\
\end{array}$ & $\begin{array}{l}35.0 \\
33.0 \\
27.1 \\
4.9 \\
0\end{array}$ \\
\hline
\end{tabular}




\begin{tabular}{lll}
\hline 4. Pendapatan Keluarga / (SES) & & \\
Kurang RM1000 & & \\
RM1001-RM3000 & 33 & 32.0 \\
-RM6000 & 43 & 41.7 \\
RM6001 ke atas & 17 & 16.6 \\
& 10 & 9.7
\end{tabular}

Berdasarkan Jadual 1 di atas, jumlah pelajar lelaki (52 orang pelajar ; 50.5\%) hampir sama dengan pelajar perempuan (51 orang pelajar; 49.5\%). Dari sudut kaum pula, seramai 36 orang pelajar (35\%) tingkatan dua terdiri daripada kaum Melayu dan Cina masing-masing, manakala pelajar India pula seramai 31 orang pelajar $(30 \%)$. Selain itu, seramai 36 orang pelajar $(35 \%)$ adalah beragama islam, 34 orang $(33 \%)$ murd-pelajar beragama Buddha, sementara pelajar tingkatan dua yang beragama Hindu dan Kristian masing-masing seramai 28 orang pelajar (27.1\%) dan 5 orang pelajar (4.9\%) sahaja.

Dari segi SES, daripada 103 orang responden kajian, seramai 43 orang pelajar $(41.7 \%)$ terdiri daripada keluarga yang memiliki pendapatan dari RM1001 hingga RM3000, manakala seramai 33 orang pelajar (32\%) pula datang daripada keluarga yang memiliki pendapatan keluarga kurang dari RM1000. Seterusnya, pendapatan keluarga pelajar yang berada antara RM3001 hingga RM6000 adalah seramai 17 orang pelajar (16.5\%), manakala pelajar yang terdiri daripada pendapatan keluarga melebihi RM6001 adalah 10 orang pelajar (9.7\%). Melihat kepada pendapatan keluarga responden kajian, tangga gaji di antara RM1001 hingga RM3000 menunjukkan bilangan yang paling ramai berbanding yang lain.

\section{DAPATAN KAJIAN DAN PERBINCANGAN}

Kajian ini menjawab tiga soalan kajian utama. Bahagian ini memaparkan data yang telah dianalisis daripada kajian yang telah dijalankan.

\section{Apakah tahap kekerapan teks KOMSAS yang menerapkan elemen perpaduan?}

Sebelum menjawab soalan kajian ini, sebanyak 16 teks KOMSAS dikenal pasti membawa elemen perpaduan kaum, antaranya termasuklah lima pantun, sebuah syair, tiga sajak moden, sebuah prosa tradisional, tiga buah cerpen, sebuah drama dan sebuah novel. Jadual 2 memaparkan tahap persetujuan murd-pelajar Tingkatan Dua tentang teks Komsas yang menerapkan elemen perpaduan tersebut.

Jadual 2. Tahap Kekerapan Teks komsas yang Menerapkan Nilai-Nilai Perpaduan

\begin{tabular}{|c|c|c|c|c|c|c|c|c|}
\hline Bil & Item & $\begin{array}{c}\text { Sanga } \\
\text { tTida } \\
\text { k } \\
\text { Setuju }\end{array}$ & $\begin{array}{l}\text { Tidak } \\
\text { Setuju }\end{array}$ & $\begin{array}{l}\text { Tidak } \\
\text { Pasti }\end{array}$ & Setuju & $\begin{array}{l}\text { Sangat } \\
\text { Setuju }\end{array}$ & Min & SP \\
\hline 1. & $\begin{array}{l}\text { Pantun Alam } \\
\text { Remaja } \\
\text { (Pantun) }\end{array}$ & $\begin{array}{c}3 \\
(2.9 \%)\end{array}$ & $\begin{array}{c}13 \\
(12.9 \%)\end{array}$ & $\begin{array}{c}45 \\
(43.7 \%)\end{array}$ & $\begin{array}{c}38 \\
(36.9 \%)\end{array}$ & $\begin{array}{c}4 \\
(3.9 \%)\end{array}$ & 3.26 & .840 \\
\hline 2. & $\begin{array}{l}\text { Pantun } \\
\text { Kiasan } \\
\text { (Pantun) }\end{array}$ & $\begin{array}{c}2 \\
(1.9 \%)\end{array}$ & $\begin{array}{c}13 \\
(12.6 \%)\end{array}$ & $\begin{array}{c}57 \\
(55.3 \%)\end{array}$ & $\begin{array}{c}26 \\
(25.2 \%)\end{array}$ & $\begin{array}{c}5 \\
(4.9 \%)\end{array}$ & 3.18 & .789 \\
\hline 3. & $\begin{array}{l}\text { Pantun Budi } \\
\text { (Pantun) }\end{array}$ & $\begin{array}{c}0 \\
(0 \%)\end{array}$ & $\begin{array}{c}5 \\
(4.9 \%)\end{array}$ & $\begin{array}{c}18 \\
(17.5 \%)\end{array}$ & $\begin{array}{c}45 \\
(43.7 \%)\end{array}$ & $\begin{array}{c}35 \\
(34 \%)\end{array}$ & 4.07 & .849 \\
\hline 4. & $\begin{array}{l}\text { Pantun } \\
\text { Nasihat } \\
\text { (Pantun) }\end{array}$ & $\begin{array}{c}1 \\
(1.0 \%)\end{array}$ & $\begin{array}{c}3 \\
(2.9 \%)\end{array}$ & $\begin{array}{c}18 \\
(17.5)\end{array}$ & $\begin{array}{c}39 \\
(37.9 \%)\end{array}$ & $\begin{array}{c}42 \\
(40.8 \%)\end{array}$ & 4.15 & .879 \\
\hline 5. & $\begin{array}{l}\text { Pantun Kasih } \\
\text { Sayang } \\
\text { (Pantun) }\end{array}$ & $\begin{array}{c}5 \\
(4.9 \%)\end{array}$ & $\begin{array}{c}13 \\
(12.6 \%)\end{array}$ & $\begin{array}{c}40 \\
(38.8 \%)\end{array}$ & $\begin{array}{c}25 \\
(24.3 \%)\end{array}$ & $\begin{array}{c}20 \\
(19.4 \%)\end{array}$ & 3.41 & 1.09 \\
\hline
\end{tabular}




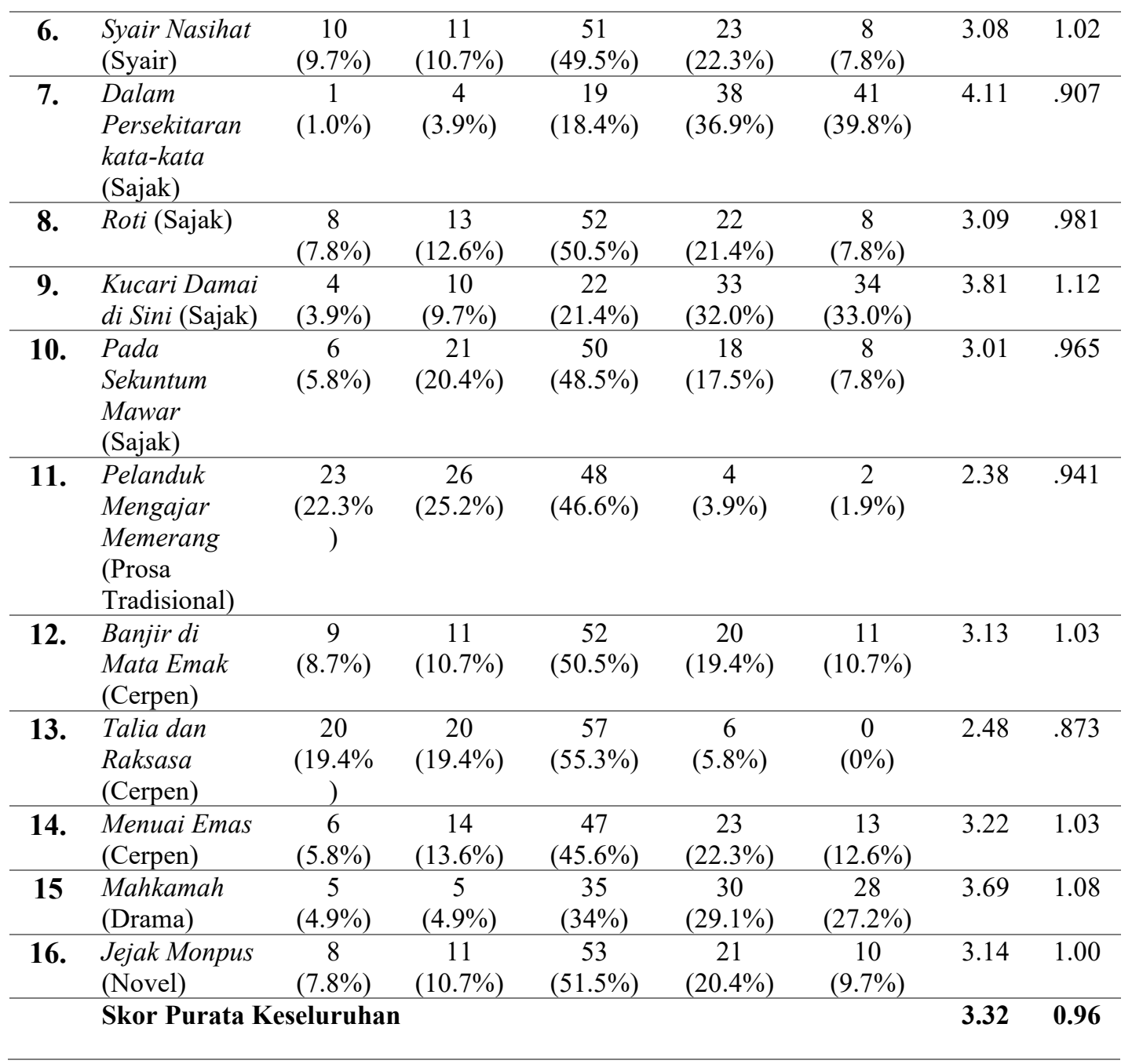

Jadual 2 menunjukkan kekerapan teks sastera yang menerapkan elemen perpaduan dalam kalangan pelajar tingkatan dua di Merlimau, Melaka berada pada tahap sederhana dengan nilai skor purata 3.32 dan sisihan piawai purata 0.96 . Hal ini demikian kerana karya sastera lain yang terkandung dalam buku teks KOMSAS tingkatan dua Edisi Melaka tidak menerapkan nilai perpaduan secukupnya. Oleh yang demikian, pihak kementerian perlulah menambahkan bilangan teks KOMSAS yang menerapkan nilai perpaduan agar nilai integrasi nasional dalam diri pelajar dapat dipupuk dengan lebih berkesan.

Hasil dapatan kajian yang diperoleh daripada 103 orang pelajar Tingkatan 2 yang menunjukkan pelajar memberikan persetujuan yang paling tinggi pada "Pantun Nasihat" $(\mathrm{M}=4.15, \mathrm{SP}=0.879)$. "Pantun Nasihat" karya Harun Mat Piah yang menjadi salah satu teks KOMSAS dalam Antologi Baik Budi, Indah Bahasa. Beberapa bait rangkap dalam pantun ini memaparkan elemen integrasi nasional seperti berikut:

\footnotetext{
Anak Cina membawa surat,

Dari Perak langsung ke Deli;

Hidup di dunia biar beradat,

Bahasa tidak dijual beli.

Pisang kelat digonggong helang, Jatuh ke lubuk lnderagiri;

Jikalau berdagang ke rantau orang, Baik-baik membawa diri.
} 
Rangkap ke 6 dan 7 dalam teks pantun ini menunjukkan elemen hidup bermasyarakat. Rangkap ke 6 membawa maksud kita hendaklah beradat ketika hidup di dunia dan bahasa itu tidak dapat dijual beli dan manakala rangkap ke 7 membawa maksud para perantau dinasihatkan agar pandai membawa diri di tempat lain. Oleh yang demikian, penyair menunjukkan kata-kata nasihat kepada semua kaum dalam menghargai Bahasa Melayu, iaitu bahasa rasmi negara ini kerana bahasa itu sangatlah bernilai. Apabila seorang perantau pergi merantau, dia hendaklah pandai membawa diri dan menjaga nama baik negara. Tambahan lagi, tema nasihat dalam pantun ini juga boleh dijadikan panduan hidup masyarakat agar sentiasa melakukan kebaikan. Pelanggaran norma masyarakat akan membawa keburukan dalam kehidupan.

Selain pantun tersebut, pantun "Dalam Persekitaran kata-kata" $(\mathrm{M}=4.11, \mathrm{SP}=0.907)$ dan "Pantun Budi" ( $\mathrm{M}=4.09, \mathrm{SP}=0.849)$ juga dipersetujui ramai bahawa ia menerapkan elemen perpaduan. Sebaliknya Prosa Tradisional "Pelanduk Mengajar Memerang" $(\mathrm{M}=2.38, \mathrm{SP}=0.941)$ dan cerpen "Talia dan Raksasa" ( $\mathrm{M}=2.48, \mathrm{SP}=0.873)$ didapat membawa elemen perpaduan. Hasil kajian ini mirip dengan dapatan Mohd Mahzan Awang, Noor Azam Abdul Rahman, Noraziah Mohd Amin dan Abdul Razaq Ahmad (2016) bahawa hanya terdapat sedikit peribahasa berkaitan perpaduan dalam buku teks Bahasa Malaysia Tingkatan 4 dan 5 yang diterapkan.

Daripada perbincangan di atas, dapat dirumuskan bahawa genre sastera yang menerapkan elemen perpaduan yang paling banyak terdapat dalam pantun, sebaliknya genre sastera lain seperti prosa tradisional, syair, dan cerpen kurang menerapkan unsur perpaduan dalam teks KOMSAS yang dikaji. Maka genre lain seharusnya memperbanyakkan elemen-elemen perpaduan yang boleh dijadikan asas kehidupan bersama masyarakat.

\section{Apakah keadaan pelaksanaan pendidikan sastera perpaduan menerusi teks KOMSAS?}

Jadual 3. Pelaksanaan Pendidikan Sastera Perpaduan menerusi teks KOMSAS

\begin{tabular}{|c|c|c|c|c|c|c|c|c|}
\hline Bil & Item & $\begin{array}{c}\text { Sangat } \\
\text { Tidak } \\
\text { Setuju }\end{array}$ & $\begin{array}{l}\text { Tidak } \\
\text { Setuju }\end{array}$ & $\begin{array}{l}\text { Tidak } \\
\text { Pasti }\end{array}$ & Setuju & $\begin{array}{l}\text { Sangat } \\
\text { Setuju }\end{array}$ & Min & SD \\
\hline 1. & $\begin{array}{l}\text { Diterapkan } \\
\text { semasa } \\
\text { pelaksanaan } \\
\text { Pentaksiran } \\
\text { Berasaskan } \\
\text { Sekolah. }\end{array}$ & $\begin{array}{c}11 \\
(10.7 \%)\end{array}$ & $\begin{array}{c}10 \\
(9.7 \%)\end{array}$ & $\begin{array}{c}33 \\
(32.0 \%)\end{array}$ & $\begin{array}{c}32 \\
(31.1 \%)\end{array}$ & $\begin{array}{c}17 \\
(16.5 \%)\end{array}$ & 3.33 & 1.18 \\
\hline 2. & $\begin{array}{l}\text { Diterapkan di } \\
\text { luar kelas }\end{array}$ & $\begin{array}{c}5 \\
(4.9 \%)\end{array}$ & $\begin{array}{c}11 \\
(10.7 \%)\end{array}$ & $\begin{array}{c}36 \\
(35.0 \%)\end{array}$ & $\begin{array}{c}32 \\
(31.1 \%)\end{array}$ & $\begin{array}{c}19 \\
(18.4 \%)\end{array}$ & 3.48 & 1.06 \\
\hline 3. & $\begin{array}{l}\text { Pelajar } \\
\text { bertanya } \\
\text { kepada guru } \\
\text { dalam kelas. }\end{array}$ & $\begin{array}{c}3 \\
(2.9 \%)\end{array}$ & $\begin{array}{c}5 \\
(4.9 \%)\end{array}$ & $\begin{array}{c}19 \\
(18.4 \%)\end{array}$ & $\begin{array}{c}42 \\
(40.8 \%)\end{array}$ & $\begin{array}{c}34 \\
(33.0 \%)\end{array}$ & 3.96 & .989 \\
\hline 4. & $\begin{array}{l}\text { Guru } \\
\text { bersungguh- } \\
\text { sungguh untuk } \\
\text { mengajar teks } \\
\text { KOMSAS } \\
\text { bertemakan } \\
\text { perpaduan di } \\
\text { kelas. }\end{array}$ & $\begin{array}{c}2 \\
(1.9 \%)\end{array}$ & $\begin{array}{c}6 \\
(5.8 \%)\end{array}$ & $\begin{array}{c}27 \\
(26.2 \%)\end{array}$ & $\begin{array}{c}32 \\
(31.1 \%)\end{array}$ & $\begin{array}{c}36 \\
(35.0 \%)\end{array}$ & 3.91 & 1.01 \\
\hline 5. & $\begin{array}{l}\text { Guru mampu } \\
\text { menarik minat } \\
\text { pelajar untuk } \\
\text { mempelajari } \\
\text { teks KOMSAS } \\
\text { bertema } \\
\text { perpaduan. }\end{array}$ & $\begin{array}{c}4 \\
(3.9 \%)\end{array}$ & $\begin{array}{c}8 \\
(7.8 \%)\end{array}$ & $\begin{array}{c}33 \\
(32 \%)\end{array}$ & $\begin{array}{c}33 \\
(32 \%)\end{array}$ & $\begin{array}{c}25 \\
(24.3 \%)\end{array}$ & 3.65 & 1.05 \\
\hline
\end{tabular}




\begin{tabular}{|c|c|c|c|c|c|c|c|c|}
\hline 6. & $\begin{array}{l}\text { Guru } \\
\text { menerapkan } \\
\text { nilai } \\
\text { perpaduan } \\
\text { antara kaum } \\
\text { semasa } \\
\text { pengajaran } \\
\text { KOMSAS. }\end{array}$ & $\begin{array}{c}9 \\
(8.7 \%)\end{array}$ & $\begin{array}{c}9 \\
(8.7 \%)\end{array}$ & $\begin{array}{c}32 \\
(31.1 \%)\end{array}$ & $\begin{array}{c}33 \\
(32 \%)\end{array}$ & $\begin{array}{c}20 \\
(19.4 \%)\end{array}$ & 3.45 & 1.16 \\
\hline 7. & $\begin{array}{l}\text { Teks } \\
\text { KOMSAS } \\
\text { bertemakan } \\
\text { perpaduan } \\
\text { mudah } \\
\text { difahami } \\
\text { semua kaum. }\end{array}$ & $\begin{array}{c}6 \\
(5.8 \%)\end{array}$ & $\begin{array}{c}16 \\
(15.5 \%)\end{array}$ & $\begin{array}{c}39 \\
(37.9 \%)\end{array}$ & $\begin{array}{c}27 \\
(26.2 \%)\end{array}$ & $\begin{array}{c}15 \\
(14.6 \%)\end{array}$ & 3.28 & 1.08 \\
\hline 8. & $\begin{array}{l}\text { Terdapat } \\
\text { pelbagai isu } \\
\text { yang menarik } \\
\text { dalam teks } \\
\text { KOMSAS } \\
\text { bertemakan } \\
\text { perpaduan. }\end{array}$ & $\begin{array}{c}2 \\
(1.9 \%)\end{array}$ & $\begin{array}{c}9 \\
(8.7 \%)\end{array}$ & $\begin{array}{c}39 \\
(37.9 \%)\end{array}$ & $\begin{array}{c}36 \\
(35.0 \%)\end{array}$ & $\begin{array}{c}17 \\
(16.5 \%)\end{array}$ & 3.55 & .936 \\
\hline 9. & $\begin{array}{l}\text { KOMSAS } \\
\text { meliputi semua } \\
\text { kaum di } \\
\text { Malaysia }\end{array}$ & $\begin{array}{c}7 \\
(6.8 \%)\end{array}$ & $\begin{array}{c}4 \\
(3.9 \%)\end{array}$ & $\begin{array}{c}33 \\
(32.0 \%)\end{array}$ & $\begin{array}{c}34 \\
(33.0 \%)\end{array}$ & $\begin{array}{c}25 \\
(24.3 \%)\end{array}$ & 3.64 & 1.10 \\
\hline 10. & $\begin{array}{l}\text { Saya gembira } \\
\text { mempelajari } \\
\text { KOMSAS } \\
\text { bertemakan } \\
\text { perpaduan. }\end{array}$ & $\begin{array}{c}7 \\
(6.8 \%)\end{array}$ & $\begin{array}{c}12 \\
(11.7 \%)\end{array}$ & $\begin{array}{c}26 \\
(25.2 \%)\end{array}$ & $\begin{array}{c}29 \\
(28.2 \%)\end{array}$ & $\begin{array}{c}29 \\
(28.2 \%)\end{array}$ & 3.59 & 1.21 \\
\hline 11. & $\begin{array}{l}\text { Saya } \\
\text { mempelajari } \\
\text { nilai positif } \\
\text { dalam teks } \\
\text { KOMSAS } \\
\text { bertemakan } \\
\text { perpaduan. }\end{array}$ & $\begin{array}{c}5 \\
(4.9 \%)\end{array}$ & $\begin{array}{c}6 \\
(5.8 \%)\end{array}$ & $\begin{array}{c}33 \\
(32.0 \%)\end{array}$ & $\begin{array}{c}36 \\
(35 \%)\end{array}$ & $\begin{array}{c}23 \\
(22.3 \%)\end{array}$ & 3.64 & 1.07 \\
\hline 12. & $\begin{array}{l}\text { Saya sering } \\
\text { membantu } \\
\text { rakan untuk } \\
\text { memahami } \\
\text { teks KOMSAS } \\
\text { bertemakan } \\
\text { perpaduan. }\end{array}$ & $\begin{array}{c}5 \\
(4.9 \%)\end{array}$ & $\begin{array}{c}5 \\
(4.9 \%)\end{array}$ & $\begin{array}{c}34 \\
(33 \%)\end{array}$ & $\begin{array}{c}40 \\
(38.8 \%)\end{array}$ & $\begin{array}{c}19 \\
(18.4 \%)\end{array}$ & 3.61 & 1.00 \\
\hline 13. & $\begin{array}{l}\text { Saya } \\
\text { mengetahui } \\
\text { budaya rakan } \\
\text { saya melalui } \\
\text { pengajaran } \\
\text { KOMSAS. }\end{array}$ & $\begin{array}{c}10 \\
(9.7 \%)\end{array}$ & $\begin{array}{c}5 \\
(4.9 \%)\end{array}$ & $\begin{array}{c}34 \\
(33 \%)\end{array}$ & $\begin{array}{c}34 \\
(33 \%)\end{array}$ & $\begin{array}{c}20 \\
(19.4 \%\end{array}$ & 3.48 & 1.15 \\
\hline \multicolumn{7}{|c|}{ Skor Purata Keseluruhan } & 3.58 & 1.07 \\
\hline
\end{tabular}

Merujuk Jadual 3, pelaksanaan pendidikan sastera perpaduan berada pada tahap sederhana iaitu nilai purata skor min sebanyak 3.58 dengan sisihan piawai purata 1.07. Oleh itu, pelaksanaan pendidikan sastera perpaduan memerlukan penambahbaikan dari semasa ke semasa.

Hasil dapatan kajian menunjukkan beberapa item yang menunjukkan persetujuan pelajar yang tinggi dalam kalangan pelajar tingkatan 2. Pernyataan "Pelajar bertanya kepada guru dalam kelas" $(M=3.96$, 
$\mathrm{SP}=0.989$ ) menunjukkan persetujuan yang paling tinggi dan positif daripada pelajar tingkatan 2 dalam kajian ini. Menurut Zamri Mahamod dan Nor Razah Lim (2011), sepanjang kaedah pemerhatian yang dijalankan kepada pelajar dalam kajiannya, kebanyakan soalan lebih banyak dikemukakan dalam tajuk KOMSAS. Hal ini kerana dalam tajuk KOMSAS dilihat penggunaannya lebih kerap dan banyak soalan yang boleh diajukan. Secara tidak langsung, pelajar menerima soalan yang diajukan dengan reaksi yang positif dengan bertanya kepada guru.

Pernyataan kedua tinggi nilai min jatuh pada "Guru bersungguh-sungguh untuk mengajar teks KOMSAS bertemakan perpaduan di kelas" $(\mathrm{M}=3.91$; $\mathrm{SP}=1.01)$. Hal ini memperlihatkan guru menyedari kepentingan menyampaikan teks KOMSAS yang menerapkan unsur perpaduan kepada para pelajar yang berbilang kaum. Dapatan kajian ini bertepatan dengan hasil kajian Chew (2009) yang mendapati bahawa guru-guru Bahasa Melayu memainkan peranan yang sangat penting untuk menyemai semangat muhibah dalam kalangan pelajar menerusi KOMSAS kerana integrasi kaum adalah tunggak pembangunan negara. Hasil ini juga selaras dengan kenyataan Yong Hie Hie, Ku Hasnita Ku Samsu, Zatul Himmah Adnan, Mohd Daud Awang dan Adlina Ab Halim (2018) bahawa guru berperanan sebagai agen sosialisasi dalam membentuk perpaduan kaum di sekolah.

Di sebalik itu, pernyataan "teks KOMSAS bertemakan perpaduan mudah difahami semua kaum" $(\mathrm{M}=3.28 ; \mathrm{SP}=1.08)$ memperolehi nilai min yang terendah, menunjukkan realiti bahawa teks KOMSAS pilihan yang bertemakan perpaduan agak susah difahami para pelajar yang mempunyai latar belakang kaum, agama dan budaya yang berbeza. Hal ini demikian kerana kebanyakan teks KOMSAS yang menerapkan elemen perpaduan terdiri daripada pantun yang agak susah difahami. Pantun adalah genre sastera tradisional yang mengandungi pembayang dan maksud di mana mesej disampaikan secara tersirat, dan bukannya berterus terang. Tambahan pula, gaya bahasanya yang tinggi dan berbungabunga juga menyukarkan pemahaman pelajar.

Selain itu, "diterapkan semasa pelaksanaan Pentaksiran Berasaskan Sekolah" (M=3.33; $\mathrm{SP}=1.18)$ adalah pernyataan yang kedua rendah nilai minnya. Dapatan ini menunjukkan bahawa aspek perpaduan kurang dinilai oleh guru-guru Bahasa Melayu dalam Pentaksiran Berasaskan Sekolah. Secara tidak langsung, ini menggambarkan bahawa guru-guru kurang mengambil berat tentang topik hubungan kaum dan integrasi sebagai fokus penilaian di sekolah. Hal ini boleh dikaitkan dengan sikap berhatihati guru-guru agar tidak membincangkan isu kaum, agama, dan budaya yang sensitif dalam penaksiran.

Kesimpulan hasil kajian ini menunjukkan dapatan yang positif daripada pelajar terhadap pelaksanaan pendidikan sastera perpaduan di kelas. Namun penambahbaikan masih perlu diteruskan dan diperkukuhkan kerana kurangnya minat pelajar-pelajar dalam mempelajari mata pelajaran KOMSAS dalam bahasa Melayu dan teks KOMSAS yang bertemakan perpaduan kaum kurang diselitkan atau kurang menarik. Perkara ini perlu diatasi segera demi kelangsungan kualiti pengajaran dan pembelajaran mata teks KOMSAS.

\section{Adakah terdapat perbezaan yang signifikan antara pelaksanaan pendidikan sastera perpaduan menerusi teks KOMSAS mengikut kaum dan SES?}

Perbincangan hasil kajian bermula dengan analisis ANOVA sehala terhadap kaum.

Jadual 4. Ujian Anova Pelaksanaan Pendidikan Sastera Perpaduan menerusi teks KOMSAS mengikut Kaum

\begin{tabular}{|c|c|c|c|c|c|c|}
\hline $\begin{array}{l}\text { Pelaksanaan Pendidikan } \\
\text { Sastera Perpaduan } \\
\text { berdasarkan Kaum }\end{array}$ & $\begin{array}{c}\text { Jumlah } \\
\text { Kuasa } \\
\text { Dua }\end{array}$ & $D f$ & $\begin{array}{l}\text { Min } \\
\text { Kuasa } \\
\text { Dua }\end{array}$ & $\boldsymbol{F}$ & $p$ & $\begin{array}{c}\text { Saiz } \\
\text { Kesan }\end{array}$ \\
\hline Antara Kumpulan & 9.615 & 2 & 4.808 & 11.272 & $.000 *$ & 0.184 \\
\hline \multirow[t]{2}{*}{ Dalam Kumpulan } & 42.652 & 100 & .427 & & & \\
\hline & 52.267 & 102 & & & & \\
\hline
\end{tabular}


Jadual 5. Keputusan Ujian Post Hoc Scheffe Pelaksanaan Pendidikan Sastera Perpaduan menerusi teks KOMSAS mengikut Kaum

\begin{tabular}{lllll} 
Kaum & & $\begin{array}{c}\text { Perbezaan } \\
\text { Min }\end{array}$ & $\begin{array}{c}\text { Ralat } \\
\text { Piawai }\end{array}$ & $\boldsymbol{p}$ \\
& & & & \\
\hline Melayu & Cina & $.690^{*}$ & .154 & .000 \\
Melayu & India & $.564^{*}$ & .160 & .003 \\
Cina & India & .203 & .134 & .254 \\
& & & & \\
& & & & \\
& & & \\
\end{tabular}

Dapatan kajian Ujian ANOVA sehala memperlihatkan terdapat perbezaan yang signifikan antara pelaksanaan pendidikan sastera perpaduan menerusi teks KOMSAS berdasarkan kaum $(F(2$, $100)=11.272 ; p<0.05)$. Hasil kajian juga memperincikan pelaksanaan pendidikan sastera perpaduan bagi kaum Melayu $(M=3.99$, S.P=0.775) dan kaum India $(M=3.429$. $S . P=0.624)$ adalah lebih tinggi berbanding kaum Cina $(\mathrm{M}=3.303$, S.P $=0.534)$.

Seterusnya, ujian Post Hoc Scheffe telah dijalankan lagi untuk mengetahui secara terperinci golongan kaum apa yang jelas menunjukkan perbezaan yang ketara. Merujuk jadual 5, pengkaji mendapati terdapat perbezaan yang ketara antara kaum Melayu dengan Cina (perbezaan min $=0.690$; $\mathrm{RP}=.154$ ) dan kaum Melayu dengan India (perbezaan $\min =0.564 ; \mathrm{RP}=0.16$ ). Namun begitu, kaum Cina dan India terbukti tidak menunjukkan perbezaan yang ketara dalam kajian ini. Justeru pengkaji merumuskan bahawa pelaksanaan pendidikan sastera perpaduan menerusi KOMSAS dipengaruhi oleh faktor kaum. Oleh itu, hipotesis nul pertama yang berbunyi "Tidak terdapat perbezaan yang signifikan antara pelaksanaan pendidikan sastera perpaduan menerusi teks KOMSAS mengikut kaum" diterima, sebaliknya hipotesis alternatif pertama ditolak.

Selaras dengan itu, berdasarkan kajian yang dilaksanakan kajian Chew Fong Peng (2006), situasi ini berlaku kerana pelajar bukan Melayu beranggapan bahawa mempelajari teks KOMSAS tidak menarik kerana teks KOMSAS bersifat keMelayuan atau Malay-centric. Selaras dengan kajian pendidikan sastera perpaduan ini, dapatan kajian Chew (2003) juga memaparkan bahawa terdapat perbezaan pendapat yang signifikan dalam kalangan pelajar Melayu dan bukan Melayu terhadap sastera yang menerapkan hubungan etnik. Hasil kajian ini memperkukuh lagi hasil kajian Chew lepas bahawa faktor kaum mempengaruhi penerimaan pelajar terhadap karya sastera yang membawa tema perpaduan kaum.

Perbincangan seterusnya beralih kepada faktor SES terhadap teks komsas yang menerapkan unsur perpaduan.

Jadual 6. Ujian Anova Pelaksanaan Pendidikan Sastera Perpaduan menerusi teks KOMSAS mengikut SES

\begin{tabular}{llllll}
\hline $\begin{array}{l}\text { Pelaksanaan Pendidikan Sastera } \\
\text { Perpaduan berdasarkan SES }\end{array}$ & $\begin{array}{l}\text { Jumlah } \\
\text { Kuasa } \\
\text { Dua }\end{array}$ & $\boldsymbol{d f}$ & $\begin{array}{l}\text { Min } \\
\text { Kuasa } \\
\text { Dua }\end{array}$ & $\boldsymbol{F}$ & Sig. \\
\hline Antara Kumpulan & 2.533 & 3 & .844 & 1.680 & .176 \\
Dalam Kumpulan & 49.735 & 99 & .502 & & \\
\hline & 52.267 & 102 & & & \\
\hline
\end{tabular}

Dapatan kajian ini menunjukkan tidak terdapat perbezaan yang signifikan antara pelaksanaan pendidikan sastera perpaduan berdasarkan $\operatorname{SES}(F(3,99)=1.680 ; p>0.05)$. Dapatan ini memperlihatkan pelaksanaan pendidikan sastera perpaduan bagi pendapatan keluarga yang bergaji RM1001-RM3000 $(\mathrm{M}=3.70, \mathrm{~S} . \mathrm{P}=0.654)$ dan pendapatan keluarga bergaji kurang daripada $\mathrm{RM} 1000(\mathrm{M}=3.378, \mathrm{~S} . \mathrm{P}=0.670)$ adalah lebih tinggi berbanding pendapatan keluarga yang bergaji RM3001 hingga $6000(\mathrm{M}=3.552$. $\mathrm{S} . \mathrm{P}=0.764)$ dan pendapatan keluarga $\mathrm{RM} 6001$ ke atas $(\mathrm{M}=3.823$, $\mathrm{S} . \mathrm{P}=0.946)$. Pengkaji dalam kajian 
ini juga merumuskan bahawa pelaksanaan pendidikan sastera perpaduan tidak dipengaruhi oleh pendapatan keluarga/SES berdasarkan keputusan kajian yang diperoleh dalam kajian ini. Oleh itu, hipotesis nul kedua yang berbunyi "Tidak terdapat perbezaan yang signifikan antara pelaksanaan pendidikan sastera perpaduan menerusi teks KOMSAS mengikut SES" ditolak, sebaliknya hipotesis alternatif kedua diterima.

Namun begitu, hasil kajian Chew Fong Peng (2003) menunjukkan dapatan yang sebaliknya, iaitu terdapat perbezaan yang signifikan penerapan elemen perpaduan melalui karya sastera mengikut SES. Kajian tersebut menjelaskan bahawa prasarana mempengaruhi pengalaman pelajar belajar khusus dalam bidang sastera. Perbezaan hasil kajian ini disebabkan jumlah responden kajian yang sedikit dalam kajian ini, iaitu hanya sebanyak 102 orang berbanding kajian Chew yang seramai 1,600 orang.

\section{KESIMPULAN}

Daripada hasil kajian ini, didapati pelajar-pelajar memberi reaksi positif terhadap pendidikan sastera perpaduan menerusi genre pantun, sajak dan juga drama dalam buku teks KOMSAS Tingkatan Dua di Melaka. Pelaksanaan pendidikan sastera perpaduan juga berada pada tahap yang sederhana. Hasil kajian ini mendapati bahawa faktor kaum mempengaruhi penerimaan pelajar-pelajar dalam pembelajaran KOMSAS yang bertemakan perpaduan kaum. Maka, diharap kajian ini dapat memberi pengetahuan yang luas dalam bidang KOMSAS dalam Bahasa Melayu di sekolah dari aspek tahap kekerapan teks KOMSAS, pelaksanaan dan faktor-faktor yang mempengaruhi pelaksanaan pendidikan sastera perpaduan ini khususnya dari sudut kaum. Oleh hal yang demikian, semua pihak termasuk Kementerian Pendidikan Malaysia, Jabatan Pendidikan Negeri, Pejabat Pendidikan Daerah, pentadbir-pentadbir sekolah, guru-guru Bahasa Melayu dan pelajar-pelajar perlu berinisiatif untuk memanfaatkan teks KOMSAS yang bertemakan perpaduan kaum bukan sahaja dalam pengajaran dan pembelajaran, tetapi juga diterapkan dalam kehidupan seharian dalam usaha melahirkan masyarakat Malaysia yang bersatu padu, aman damai dan harmoni.

\section{RUJUKAN}

Ani Omar. (2015). Pendidikan Sastera Remaja di Malaysia dalam Membina Generasi Unggul Berasaskan Falsafah Pendidikan Negara. PENDETA- Jurnal Bahasa dan Sastera Melayu, 5, 1-23.

Chew Fong Peng. (2003). Peranan sastera kebangsaan dan persepsi dalam pembentukan perpaduan nasional: satu kajian di negeri Selangor dan Wilayah Persekutuan Kuala Lumpur. Tesis Doktor Falsafah. Universiti Kebangsaan Malaysia.

Chew Fong Peng. (2006). Pembentukan Negara Bangsa Melalui Pendidikan Sastera. Jurnal Pengajian Melayu, $17,136-168$.

Chew Fong Peng (2009). Pendidikan sastera perpaduan menerusi KOMSAS Tingkatan 4: pelaksanaan dan kesannya. Jurnal Pendidikan Malaysia, 34 (2): 15-31.

Chong Chee Keong, Muhammad Faizal A. Ghani \& Zuraidah Abdullah. (2016). Amalan Komuniti Pembelajaran Profesional (KPP) Di Sekolah Berprestasi Tinggi (Sbt) Malaysia: Sebuah Sekolah Jenis Kebangsaan Cina (SJKC) di Sarawak. Jurnal Kepimpinan Pendidikan, 3(1), 43-70.

Chua Yan Piaw. (2014). Kaedah Penyelidikan. Kuala Lumpur: McGraw-Hill.

Hussein Ahmad \& Haneza Ab. Hamid. (2015). Pengurusan Pembangunan Konsep Perpaduan Dalam Kalangan Pelajar Sekolah Menengah Kebangsaan Satu Kajian Di Klang, Selangor. Jurnal Kepimpinan Pendidikan,2(4), 1-15.

Ibrahim Rosli (2016) Analisis konsep perpaduan kaum dalam novel terpilih Abdullah Hussain. Doctoral thesis, Universiti Pendidikan Sultan Idris.

Krejcie, R.V., \& Morgan, D.W. (1970). Determining Sample Size for Research Activities. Educational and Psychological Measurement, 30, 607-610

Mahzan Arshad, Abdul Jalil Othman \& Nurfatimah Awang Da. (2011) Peranan kesusasteraan pelbagai budaya dalam pembentukan perpaduan kebangsaan di Malaysia. Masalah Pendidikan, 34, . 81-98.

Mohd Mahzan Awang, Noor Azam Abdul Rahman, Noraziah Mohd Amin \& Abdul Razaq Ahmad (2015). Mesej Perpaduan dalam Buku Teks Bahasa Malaysia Tingkatan 4 \& 5: Analisis Terhadap Peribahasa Melayu. Jurnal Pendidikan Bahasa Melayu, 5(1), 44-52. 
Mohd Ridhuan Tee Abdullah. (2015). Cabaran Integrasi Antara Kaum Di Malaysia: Perspektif Media, Pertubuhan Bukan Kerajaan dan Parti Politik. Jurnal Hadhari, 7(1), 33-59.

Nurhamizah Hashim, Nur Yuhanis Mohd Nasir, Hashim Ismail, Eizah Mat Hussain \& Nurul Syahidah Tahir. (2018). Resepsi Pelajar Terhadap Teks Komsas Jendela Menghadap Jalan. Pendeta Journal of Malay Language, Education and Literature, 9, 1-15.

Suzana Sulaiman. (2013). Perpaduan Pelajar Pelbagai Etnik: Kehidupan Seharian Pelajar Program Diploma Tahun Dua, Sesi Pengajian 2012/2013, Universiti Malaysia Perlis. Proceeding of the International Conference on Social Science Research, ICSSR 2013 (hlm 1600-1605). 4-5 June 2013, Penang, MALAYSIA

Weiner, M. 1965. Political integration and political development. Annual of American Academy of Political and Social Science, 358, 52-64.

Yong Hie Hie, Ku Hasnita Ku Sams u, Zatul Himm ah Adnan, Mohd Daud Awang \& Adlina Ab Halim. (2018). Peranan Guru Sebagai Agen Sosialisasi dalam Membentuk Perpaduan Kaum di Sekolah. Akademika, 88(2), 95-108.

Zamri Mahamod, and Nor Razah Lim, (2011) Kepelbagaian kaedah penyoalan lisan dalam pengajaranguru bahasa melayu: kaedah pemerhatian. Jurnal Pendidikan Bahasa Melayu, 1 (1). pp. 51-65. 